\title{
Terapeuter som etterlatte ved selvmord
}

\author{
Ved Herbert Hendin
}

\begin{abstract}
Undersøkelser har vist at omkring halvparten av alle psykiatere og $25 \%$ av alle psykologer har mistet en pasient i selvmord (Chemtob et al., 1988a; Chemtob et al., 1988b). De fleste ser på dette som det mest traumatiske de har opplevd i sin yrkeskarriere. I denne artikkelen vil vi rapportere fra en undersøkelse som viser faktorer som bidrar til å gjøre denne opplevelsen spesielt traumatisk for et betydelig antall terapeuter. Vi vil se på hvilke følelsesmessige reaksjoner som skiller terapeuter med en sterk stressreaksjon fra de andre. Vi vil dernest ta for oss situasjonsbetingede faktorer i forbindelse med pasientens selvmord, og hvilket forhold terapeuten hadde til pasienten før selvmordet.
\end{abstract}

Chemtob et al. (1988a; 1988b) viser at det å miste en pasient i selvmord i særlig grad påvirker unge og uerfarne klinikere, noe som blir bekreftet i studier av terapeuters reaksjoner på sel vmord blant pasienter i psykiatriske døgninstitusjoner (Brown, 1987a; Brown, 1987b; Ellis et al., 1998). V årt tidligere arbeid ( $H$ endin et al., 2000) og andre undersøkelser ( A lexander et al., 2000; G itlin, 1999; Kahne, 1968; Litman, 1965; M arshall, 1980; M enninger, 1991; $\mathrm{N}$ eil et al., 1974) viser at klinikere som mister en pasient i selvmord, kan reagere på liknende måte som familiemedlemmer og venner med sjokk, sorg, skyldfølelse og sinne.

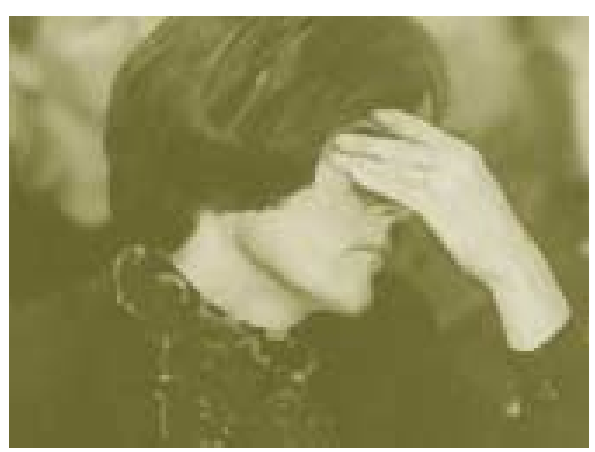

Selv om praktisk talt alle disse undersøkel sene viste at noen terapeuter får en sterkere stressreaksjon enn andre, var det ikke blitt systematisk undersøkt hvilke følelsesmessige reaksjoner som skiller terapeuter med en sterk stressreaksjon fra de andre. Vi har heller ikke funnet undersøkelser som relaterer terapeuters stressreaksjon til situasjonsbetingede faktorer i forbindelse med pasientens selvmord, eller til hvilket forhold terapeuten hadde til pasienten før selvmordet. Denne rapporten fra en undersøkelse som vi holder på med, tar for seg faktorer som bidrar til å gjøre opplevelsen av en pasients selvmord spesielt traumatisk for et betydelig antall terapeuter (H endin et al., 2004).

\section{Metode}

Terapeutene ble rekruttert til undersøkelsen gjennom flere kanaler. Vi annonserte blant annet i psykiatriske publikasjoner og sendte forespørsler via aktuelle medlemslister. M ange kom med i undersøkelsen via pårørende til pasienter som døde ved selvmord. 34 terapeuter deltok i undersøkelsen, 25 menn og 9 kvinner. Det var 28 psykiatere, fem psykologer og en klinisk sosionom. 15 terapeuter hadde behandlet pasienten i privat praksis, 19 innenfor en institusjon. $\mathrm{N} \mathrm{i}(26,5 \%)$ hadde praktisert i 15 àr eller mer, syv $(20,6 \%)$ i 10-14 år, ni $(26,5 \%)$ i 5-9 år, og ni $(26,5 \%)$ i mindre enn 5 år. Syv av terapeutene i den siste kategorien var fortsatt under utdanning da selvmordet skjedde. $H$ ver terapeut måtte fylle ut flere semistrukturerte spørreskjemaer om pasienten og gi en detaljert beskrivelse av pasientens kasus. Terapeutene måtte også fylle ut et spørreskjema med både åpne og strukturerte spørsmålsstillinger som tok for seg deres egne reaksjoner. Terapeutene rangerte ni følelsesmessige reaksjoner - sjokk, sorg, skyldfølelse, følelse av utilstrekkelighet, sinne, angst, følelse av svik, skam eller forlegenhet, samt depresjon - på en ordinal skala ("ingen," "minimal," "moderat," "intens"). De rangerte også hvor sterk stressreaksjonen var totalt sett på en skala fra 1 ("ingen stressreaksjon") til 10 ("alvorlig stressreaksjon"), hvor 7 eller mer ble betraktet som en sterk stressreaksjon. I tillegg ble terapeutene bedt om å beskrive hva de trodde var av størst betydning for at de fikk stressreaksjonen.

Etter at de hadde besvart alt det skriftlige materialet, deltok to terapeuter av gangen på et hel dags arbei dsseminar sammen med oss. Der ble deres to pasientkasus presentert og diskutert i detalj. I mange tilfeller viste det seg at vi fikk et annet bilde av terapeutens stressreaksjon gjennom denne presentasjonen og diskusjonen enn det terapeuten hadde gitt oss på papiret. D et gjaldt enten rangeringen av reaksjonen eller grunnen til den eller begge deler. Disse forskjellene ble diskutert på arbeidsseminaret, og terapeuten og de andre deltakerne kom i fellesskap fram til en konklusjon.

De 34 pasientene som var beskrevet av terapeutene i undersøkelsen, var i alderen 17 til 63 år, med en gjennomsnittsalder på 37,9 år $(S D=13,6)$. Det var 18 menn og 16 kvinner. 23 pasienter var polikliniske pasienter da de utførte selvmordshandlingen. Seks av disse hadde imidlertid startet behandlingen hos terapeuten som sykehuspasient, og i to av tilfellene var pasienten blitt skrevet ut fra sykehuset like før selvmordet fant sted. De andre 11 pasientene var innlagt på sykehus eller i andre døgninstitusjoner da de gjorde selvmord. 13 (38,2\%) av de 34 pasientene hadde vært i behandling i mindre en $n$ seks måneder før selvmordet, fem $(14,7 \%)$ var blitt behandlet i 6-12 måneder, $13(38,2 \%)$ i 13-24 måneder og tre $(8,8 \%)$ i $25-60$ måneder.

I de fleste av våre analyser ble terapeutene delt inn i to grupper: de som fikk en sterk stressreaksjon etter selvmordet og de som ikke fikk det. Terapeutenes spesifikke følelser ble delt inn i to som enten intense eller ikke intense, og Fishers Exact-testen ble brukt for å måle forskjeller mellom gruppene. Forholdet mellom alvorlighetsgraden på stressreaksjonen og andre kategorivariabler ble analysert ved hjelp av Fishers Exacttesten ( to kategorier) eller kji-kvadrattester ( tre eller flere kategorier). Forholdet mellom kontinuerlige variabler ble analysert ved hjelp av tosidige t-tester for uavhengige utvalg.

U ndersøkelsen er finansiert av M ental IIIness Foundation og Janssen Pharmaceutica. A rtikkel en bygger på to tidligere artikler i A merican Journal of Psychiatry og inkluderer observasjoner basert på videre analyser av datagrunnlaget for de to artiklene. 


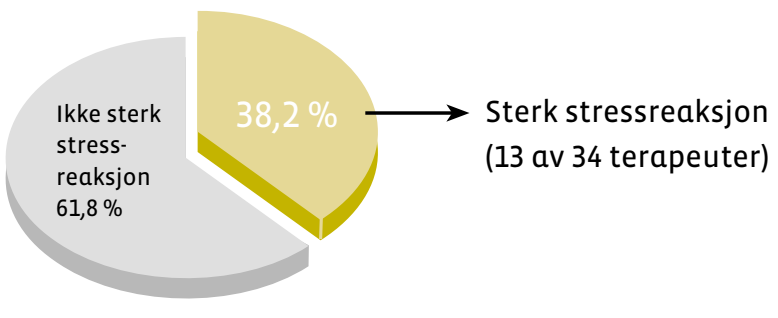

\section{Resultater}

13 av de 34 terapeutene ( $38,2 \%$ ) fikk en sterk stressreaksjon etter pasientens selvmord. H os disse 13 skyldtes dette en av følgende fire faktorer:

\section{$M$ islyktes i å få pasienten innlagt}

I tre tilfeller kom terapeutens sterke stressreaksjon av at han/hun ikke hadde fått lagt inn en pasient som så gjorde selvmord. I alle disse tilfellene hadde pasienten gjort det klart i den siste samtalen at han/hun hadde til hensikt å ta livet av seg. A lle de tre terapeutene skjønte at pasienten var i en selvmordskrise, men ingen av dem var i stand til å gripe inn og insistere på innleggelse. En psykiater med over 30 års praksis rådet pasienten innstendig til å la seg innlegge. Pasienten sa at han skulle vurdere det, men dro hjem og tok livet av seg. I alle de tre tilfellene var det selve terapiformen som hindret terapeuten i å få lagt inn den uvillige pasienten fordi pasienten selv hadde kontroll over hva som skulle eller ikke skulle snakkes om, om og hvor mye medisiner som skulle brukes osv.

\section{E $\mathbf{n}$ behandlingsavgjørelse}

Fire terapeuter, som alle hadde mellom 7 og 12 års erfaring, var sterkt plaget av en behandlingsavgjørelse som de følte hadde bidratt til selvmordet. I ett tilfelle lot en psykiater seg overtale av den sosialt framstående onkelen til en av de suicidale pasientene som var innlagt på avdelingen, til å la pasienten gå ut og spise middag med onkelen. Pasienten stakk av og dro hjem og skjøt seg.

En annen terapeut forsto allerede tidlig i behandlingen av en suicidal kvinnelig pasient at hennes mulighet til å få pasienten innlagt var liten i forhold til pasientens mulighet til å ta livet av seg uten at terapeuten visste det. Dette forholdet dannet grunnlaget for en allianse som vedvarte i over et år med terapi. Da pasienten røpet at hun følte seg suicidal, men ikke hadde lyst til å snakke om det, truet terapeuten med innleggelse. Dette fikk pasienten til å late som om hun var bedre i mange uker mens hun bestemte seg for og planla selvmord. Lydopptak som pasienten etterlot seg, viste i detalj ikke bare hennes eget bedrag, men også at hun følte at terapeutens trussel var et svik.
I de to andre tilfellene hadde terapeutene gjennom len gre tid prøvd à overtale pasientene til å forlate en institusjon der de fungerte ganske godt, til tross for tegn som tydet på at pasientene ikke var klare for å bo for seg selv. En av terapeutene ga etter for press fra moren til en 39 år gammel, bipolar pasient om å la ham flytte ut av en gruppebolig. M ens utflyttingen ble planlagt, fortalte pasienten til dem han bodde sammen med at han ville drukne seg og viste dem tau og betongblokker som han hadde samlet for dette formålet. Terapeuten ble varslet og konfiskerte tingene. $\mathrm{H}$ an tolket disse forberedelsene som motstand mot forandringer og fortsatte å oppmuntre pasienten til å flytte til en egen leilighet. Kort etter festet pasienten vekter til kroppen og druknet akkurat slik han hadde planlagt.

\section{$\mathrm{N}$ egative reaksjoner fra terapeutens institusjon}

I to tilfeller fikk terapeuten en sterk stressreaksjon på grunn av institusjonens reaksjon på selvmordet. I begge tilfeller dreide det seg om terapeuter under utdanning som følte at sykehusets administrasjon ga dem skylden for pasientens selvmord. En av terapeutene, som arbeidet på en kommunal sykehuspoliklinikk, hadde behandlet en 23 år gammel kvinne med sterk depresjon, rusproblemer og selvmordstanker. $\mathrm{H}$ an hadde vært frustrert over at pasienten virket lite engasjert $\mathrm{i}$ behandlingen. $\mathrm{H}$ un kom stadig for sent til de ukentlige terapitimene, fortal te at hun likte sin tidligere kvinnelige terapeut bedre og fortsatte å drikke alkohol og misbruke narkotika. Hun døde av en overdose i leiligheten sin mens de hun delte leilighet med, hygget seg i naborommet. U nder en selvmordsgjennomgang i etterkant så lederen for sykehusklinikken rett på terapeuten og sa: "(Pasienten) døde tydeligvis på samme måte som hun ble behandlet, med mange mennesker rundt seg, men ingen som kunne gi henne effektiv hjelp".

En annen terapeut, som fikk vite om sin polikliniske pasients selvmord da han ankom sykehuset, skrev: "(Jeg) gikk omtåket til kontoret mitt og oppdaget at klinikklederen hadde låst seg inn og lette gjennom skrivebordet mitt etter pasientjournalen. Jeg var helt satt ut og ble ikke sint på ham der og da, men nå kommer sinnet opp igjen mens jeg skriver dette. Jeg husker at jeg satt ved skrivebordet mitt og stirret tomt ut i luften i noe som virket som en evighet selv om det bare var noen få minutter. Jeg var ikke mentalt til stede hos de neste pasientene mine og begynte å stille spørsmål ved alle avgjørel ser jeg tok - og ofte kunne jeg ikke tenke klart ...

\section{F rykt for søksmål}

I de fire siste tilfellene ble terapeutens stressreaksjon utløst av trusselen om søksmål fra pasientens pårørende, som ga terapeuten skylden for selvmordet. En av terapeutene mistet en 56 år gammel kvinnelig pasient som var gift med en psykiater. Pasienten var nylig blitt innlagt og behandlet for alvorlig depresjon med medisiner og elektrokonvulsiv terapi (ECT). Etter to måneder med ukentlig poliklinisk terapi var hun fortsatt sterkt deprimert og uten håp, og hun tilstod etter press fra mannen sin at hun to uker tidligere hadde brukt en av knivene hans til å skjære seg i nakken med. H un prøvde å bagatellisere hendelsen, men gikk med på å spørre ektemannen om han kunne være med henne til en terapitime. $\mathrm{H}$ un druknet seg imidlertid mens mannen var ute av huset. Ektemannen ble rasende på terapeuten og truet med søksmål. A lle de fire terapeutene som ble truet og klandret for selvmordet av pasientens pårørende, levde i mange måneder i frykt for at de måtte betale både personlig og yrkesmessig, også når det ikke kom til søksmål.

\section{H vordan stressreaksjonen kom til uttrykk}

H os de 13 terapeutene kom den sterke stressreaksjonen til uttrykk på forskjellig måte. Psykiateren med 30 års erfaring som ikke hadde fâtt lagt inn sin suicidale pasient, drømte stadig at han strøk til eksamen, noe han mente gjenspeilte en følelse av utilstrekkelighet som han ikke hadde hatt siden studietiden. En annen terapeut som ikke hadde fătt lagt inn en pasient i selvmordkrise, fikk en oversvømmelse på kontoret sitt dagen etter at hun hadde vært i pasientens begravelse. $\mathrm{H}$ un fantaserte om at vannet som strømmet nedover veggen, var tårene til de sørgende, og hun så på oversvømmelsen som en straff for at hun ikke hadde greid 
å forhindre selvmordet. En terapeut som ble saks $\varnothing \mathrm{kt}$ av pasientens kone, var fylt av et voldsomt sinne mot pasienten og kona hans fordi de hadde satt henne $\mathrm{i}$ denne situasjonen. Hun var klar over at sinnet hennes noen ganger viste seg i forholdet til andre suicidale pasienter. En annen terapeut skvatt opp i angst når telefonen hans ringte om natten i to år etter at han mistet en pasient i selvmord. Både han og en annen erfaren terapeut vurderte en stund å gi opp praksisen sin. Selv om det iblant var én følelse som dominerte en terapeuts følelsesmessige reaksjon, rapporterte terapeutene med sterk stressreaksjon gjennomgående et klart høyere antall intense følelsesmessige reaksjoner med et snitt på 4,8 av de 9 som ble unders $\varnothing \mathrm{kt}$, sammenlignet med et snitt på 2,6 hos dem som ikke fikk en sterk stressreaksjon $(t=3.53, \mathrm{df}=32, \mathrm{p}=0.001)$.

Tabell 1 nedenfor viser at intens sorg, skyldfølelse, følelse av utilstrekkelighet, angst og depresjon var klart vanligere blant terapeutene med sterk stressreaksjon enn blant de andre terapeutene. Intenst sinne, som $61,5 \%$ av terapeutene med sterk stressreaksjon opplevde, uavhengig av alder og erfaring, var nesten like vanlig hos de terapeutene som ikke fikk en sterk stressreaksjon $(57,1 \%)$.

TABELL 1: Forekomsten av intense følelsesmessige reaksjoner hos terapeuter med eller uten en sterk stressreaksjon etter å ha mistet en pasient i selvmord*

\begin{tabular}{|c|c|c|c|c|c|}
\hline \multirow{3}{*}{$\begin{array}{l}\text { Følelsesmessig } \\
\text { reaksjon }\end{array}$} & \multicolumn{4}{|c|}{ Terapeuter som opplevde følelsen som intens } & \multirow[b]{3}{*}{$\mathrm{p} * \star$} \\
\hline & \multicolumn{2}{|c|}{$\begin{array}{c}\text { Sterk } \\
\text { stressreaksjon }(\mathrm{N}=13)\end{array}$} & \multicolumn{2}{|c|}{$\begin{array}{c}\text { Ingen sterk } \\
\text { stressreaksjon }(\mathrm{N}=21)\end{array}$} & \\
\hline & $\mathrm{N}$ & $\%$ & $\mathrm{~N}$ & $\%$ & \\
\hline Sorg & 12 & 92,3 & 11 & 52,4 & 0,03 \\
\hline Skyld & 12 & 92,3 & 9 & 42,9 & 0,005 \\
\hline Utilstrekkelighet & 6 & 46,2 & 1 & 4,8 & 0,007 \\
\hline Angst & 5 & 38,5 & 0 & 0,0 & 0,005 \\
\hline Depresjon & 7 & 53,8 & 2 & 9,5 & 0,02 \\
\hline Sinne & 8 & 61,5 & 12 & 57,1 & 1,00 \\
\hline Sjokk & 8 & 61,5 & 12 & 57,1 & 1,00 \\
\hline Skam & 3 & 23,1 & 4 & 19,0 & 1,00 \\
\hline Svik & 1 & 7,7 & 2 & 9,5 & 1,00 \\
\hline
\end{tabular}

* Terapeutenes stressreaksjon ble ansett som sterk hvis de rangerte den til å være 7 eller høyere på en skala fra 1 til 10 .

** Fishers Exact-test
Som vist i Tabell 1 forekom også opplevelsen av sjokk, svik og skam noenlunde like hyppig i de to gruppene.

\section{Karakteristiske trekk ved terapeutene}

Visse kjennetegn, som kjønn, utdanningsstatus og antall års erfaring, syntes å ha innvirkning på hvor sårbare terapeutene var for å få en sterk stressreaksjon. Vi fant at kvinnelige terapeuter hadde sterk reaksjon som mannlige terapeuter. Over halvparten av de terapeutene som fortsatt var under utdanning da selvmordet skjedde, fikk en sterk reaksjon, mens bare en tredjedel av de andre terapeutene opplevde det samme. Nesten halvparten av dem som hadde praktisert i mindre enn 15 år, fikk en sterk stressreaksjon, mens det kun gjaldt for litt over $1 / 10$ av dem med over 15 års erfaring. Ingen av disse forholdene var imidlertid statistisk signifikante, noe som nok skyldes relativt lave tall i noen celler. Forskjellen mellom forekomsten av sterke stressreaksjoner hos erfarne og mindre erfarne terapeuter nærmet seg statistisk signifikans.

\section{Diskusjon}

Omtrent en tredel av terapeutene i vår unders $\varnothing$ kelse fikk en sterk stressreaksjon etter å ha mistet en pasient i selvmord. nesten dobbelt så stor risiko for å få en
Dette skyldtes en av følgende fire faktorer:

- Terapeuten fikk ikke lagt inn en pasient i selvmordskrise.

- Terapeuten følte at en behandlingsavgjørelse var en medvirkende årsak til pasientens selvmord.

- Terapeuten fikk negative reaksjoner fra sin institusjon.

- Terapeuten var redd for å bli saks $\varnothing k t$ av pasientens pårørende.

Ingen av de terapeutene som ikke fikk en sterk stressreaksjon, hadde skjønt i den siste samtalen at pasienten var i en selvmordskrise. Ingen av dem opplevde at deres egne avgjørelser i løpet av behandlingen hadde bidratt vesentlig til selvmordet. Ingen hadde opplevd bebreidelser fra sin institusjon, og selv om noen var redde for å bli saks $\varnothing \mathrm{kt}$, hadde ingen av dem blitt truet med søksmål av pasientens pårørende.

Det å forstå de spesifikke følelsesmessige reaksjonene hos terapeutene var viktig for å skjønne hva som lå bak deres stressreaksjon. To følelser, sorg og skyldfølelse, ble beskrevet som intense av nesten alle terapeutene med en sterk stressreaksjon. I nesten alle tilfellene hang terapeutenes intense sorg sammen med deres sterke følelsesmessige binding til pasienten, noe som syntes å gjøre dem sårbare for å oppleve andre følelser intenst også. Vi merket oss at det blant de terapeutene som beskrev sorgen etter pasientens $\mathrm{d} \varnothing \mathrm{d}$ som "ingen" eller "minimal", bare var én med sterk stressreaksjon.

Skyldfølelse reflekterte, på samme måte som sorg, ofte en nær følelsesmessig relasjon til pasienten heller enn kvaliteten på innsatsen som terapeut. Blant dem som fikk intens skyldfølelse, fant vi de to terapeutene som følte seg klandret av institusjonen sin og de fire som følte at pasientens pårørende ga dem skylden for selvmordet og som var redde for $s \varnothing \mathrm{ksmål.}$ I disse seks tilfellene trodde verken terapeuten selv eller de som gjorde denne unders $\varnothing$ kelsen, at terapeutens handlinger hadde bidratt til selvmordet. I noen tilfeller var det klart at pasientens pårørende unngikk å vedkjenne seg sin egen skyldfølelse ved å klandre terapeuten. Det virket også som om de institusjonslederne som bebreidet terapeuten, selv var redde for å bli klandret eller saks $\varnothing \mathrm{kt}$ av pårørende. 
U ansett førte det å bli behandlet som skyldig av engstelige institusjonsledere eller sinte pårørende til at terapeutene selv følte skyld. Blant dem som fikk intens skyldfølelse fant vi også tre av de fire terapeutene som mente, med en viss rett, at deres behandlingsavgjørelser hadde bidratt til pasientens selvmord. I midlertid hadde ingen av disse fire opplevd å bli klandret av institusjonen eller pasientens familie, og de ble heller ikke truet med søksmål.

Vi fant en liknende mangel på sammenheng mellom kvaliteten på behandlingen og terapeutens følel sesmessige reaksjon og andres reaksj oner hos de to terapeutene som vurderte å forlate psykiatrien. Ingen av disse terapeutene følte at deres handlinger hadde bidratt til selvmordet, noe de som gjorde undersøkelsen var enige i. B egge var erfarne psykiatere som følte at de hadde god kontakt med pasientene sine, og begge ble sjokkert over selvmordet. Etter en vanskelig periode, som i den ene terapeutens tilfelle ble forverret av at pasientens voksne sønn truet med søksmål, greide begge til slutt å avfinne seg med at selv kompetent behandling ikke alltid kan forhindre selvmord - og heller ikke en fiendtlig reaksjon fra pasientens familie. Begge fortsatte å behandle deprimerte og suicidale pasienter, den ene ble også en anerkjent selvmordsforsker.

Kjønn og yrkesmessig erfaring kan ha innvirkning på hvor sårbar en terapeut er for å få en sterk stressreaksjon. A t kvinnelige terapeuter oftere fikk en slik reaksjon, stemmer med andre undersøkelser som viser at kvinner har vanskeligere enn menn for å takle sorg ved dødsfall generelt (C leiren et al., 1994), og særlig ved selvmord (Fisher, 2000)).

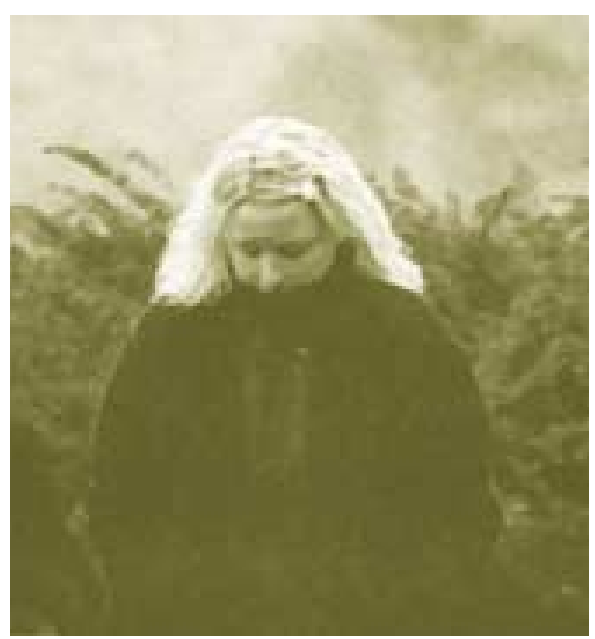

Det stemmer også med andres funn at terapeuter under utdanning er mer sårbare enn andre terapeuter for å få en stressreaksjon, særlig gjaldt dette dem som i stor grad hadde fătt et selvstendig ansvar for pasientene sine. Terapeuter under utdanning som var en del av et sykehusteam som var sammen om å fatte beslutninger angående den innlagte pasienten, følte seg oftere støttet av andre. Det var ikke så ofte de ble klandret eller følte intens skyld og fikk en sterk stressreaksjon. $M$ anglende erfaring er heller ikke den en este årsaken til sårbarhet blant terapeuter under utdanning. Selvmord på sykehus er en offentlig affære som involverer sykehusledere som er mindre tilbøyelige til å behandle erfarne terapeuter like respektløst som de uerfarne terapeutene i vår undersøkelse opplevde å bli behandlet. Lang erfaring beskyttet heller ikke dem som hadde skyldfølel se på grunn av det de opplevde som behandlingsfeil som kunne ha bidratt til selvmordet, eller dem som ble truet med søksmål. I flere tilfeller hadde det faktum at de ikke hadde opplevd et selvmord i praksisen sin på flere år, gitt dem en fal sk trygghetsfølelse som ble knust av selvmordet.

\section{Begrensninger}

De terapeutene som deltok i vår undersøkelse, hadde selv meldt seg på, og vi kan ikke vurdere hvor typiske de er for den større gruppen av terapeuter som mister pasienter i selvmord. Det kan hende at terapeuter som ikke meldte seg på undersøkelsen, enten er mer bekymret eller mindre bekymret over den behandlingen de ga enn de som var villige til å få sine kasus gjennomgått. $V$ år tidligere analyse antyder begge muligheter, og vårt senere arbeid bekrefter dette. Selv om vi ikke målte systematisk hvor lenge den sterke stressreaksjonen varte, oppga alle terapeutene med en sterk stressreaksjon at plagene varte i minst ett år etter selvmordet. H os noen av terapeutene så vi en klar bedring omtrent to år etter selvmordet. $\mathrm{N}$ oen terapeuter hadde imidlertid fortsatt sterke plager da vi møtte dem i forbindelse med undersøkelsen, og fordi vi ikke fulgte dem opp etter arbeidsseminaret, vet vi ikke hvor lenge den sterke stressreaksjonen varte ved. Varigheten av en sterk stressreaksjon kan være verd en egen undersøkelse.

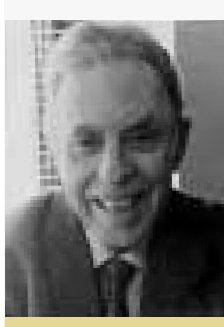

H erbert $\mathbf{H}$ endin er professor i psykiatri ved $\mathrm{N}$ ew York $M$ edical C ollege og president og administrerende direktør (CEO) i Suicide Prevention International (SPI). Verdens helseorganisasjon valgte ham nylig til en av sine to rådgivere innen selvmord.

\section{Referanser}

A lexander, D.A ., Klein, S., G ray, N .M ., Dewar, I.G ., Eagles, J.M . (2000). Suicide by patients: questionnaire study of its effect on consultant psychiatrists. BM J, 320, 1571-1574.

Brown, H.N . (1987a). T he impact of suicide on therapists in training. Compr Psychiatry, 28, 101-112.

Brown, H.N . (1987b). Patient suicide during residency training: Incidence, implications, and program response. J Psychiatr Ed, 11, 201-216.

Chemtob, C.M ., H amada, R.S., Bauer, G ., Kinney, B., Torigoe, R.Y. (1988a). Patients' suicides: frequency and impact on psychiatrists. A $\mathrm{m}$ J Psychiatry; 145, 224-228.

Chemtob, C.M ., H amada, R.S., Bauer, G ., Torigoe, R.Y., Kinney, B. (1988b). Patient suicide: frequency and impact on psychologists. Prof Psychology, $19,416-420$.

Cleiren, M .P., Diekstra, R.F., Kierkof, A .J., Van der Wal, J. (1994). M ode of death and kinship in bereavement: focusing on "who" rather than "how." Crisis, 15, 22-36.

Ellis, T.E., Dickey, T.O. III, Jones, E.C. (1988). Patient suicide in psychiatric residency programs: a national survey of training and postvention practices. A cad Psychiatry, 22, 181-189.

Fisher, P. (2000). bereavement in the families of adolescent suicide victims three years post death of the adolescents, U M I M icrofilm 9970192. A nn A rbor, M I: Bell and $\mathrm{H}$ owell Information Learning Company.

Gitlin, M .J. (1999). A psychiatrist's reaction to a patient's suicide. A mJ Psychiatry, 156, 1630-1634. H endin, H ., Lipschitz, A ., M altsberger, J.T., H aas, A .P., W ynecoop, S. (2000). T herapists' reactions to patients' suicides. A m Psychiatry, 157, 2022-2027.

Hendin, H ., H aas, A H ., M altsberger, JT., Szanto, K., Rabinowicz, H . (2004). Factors contributing to therapists' distress after the suicide of a patient. A m J Psychiatry, 161, 1442-1446, 2004.

Kahne, M.J. (1968). Suicide among patients in mental hospitals: a study of the psychiatrists who conducted their psychotherapy. Psychiatry, 31, 32-43. Litman, R.E. (1965). W hen patients commit suicide. A m J Psychotherapy, 19, 570-576.

M arshall, K.A . (1980). W hen a patient commits suicide. Suicide Life Threat Behav, 10(1):29-40.

Menninger, W.W. (1991). Patient suicide and its impact on the psychotherapist. Bull M enninger Clin, 55: 216-27.

N eill, K., Benensohn, H.S., Farber, A .N ., Resnik, H.L.P., van der W al, J. (1974). The psychological autopsy: a technique for investigating a hospital suicide. H osp Community Psychiatry, 25(1):33-6 